\title{
Fractionation and Structural Characterization of Hemicellulose from Steam-Exploded Banana Rachis
}

\author{
Mathias Florian Tiappi Deumaga ${ }^{1,5}$ - Nicolas Jacquet ${ }^{1} \cdot$ Caroline Vanderghem $^{1} \cdot$ Mario Aguedo $^{1}$. \\ Happi Guy Thomas ${ }^{2} \cdot$ Patrick Gerin $^{3} \cdot$ Magali Deleu $^{4} \cdot$ Aurore Richel $^{1}$
}

Received: 2 February 2018 / Accepted: 11 September 2018 / Published online: 17 September 2018

(c) Springer Nature B.V. 2018

\begin{abstract}
Banana production in tropical countries generates significant quantity of waste. Biorefinery of food waste biomass into cellulose, hemicellulose, lignin or pectin macromolecules have grown interest in recent scientific literature. In this paper, hemicellulose from banana rachis (Musa cavendish) was extracted by steam explosion at three severity levels (2.97, 3.57 and 3.78 ) and was further fractionated by graded ethanol precipitation method (15\%,60\% and $80 \%)$. The recovered hemicelluloses sub-fractions ( $\mathrm{H} 1, \mathrm{H} 2$ and $\mathrm{H} 3$ ) were characterized for their chemical composition and structural features by HPSEC, TGA/ DTG, FTIR, 1H and 2D NMR techniques. The hemicellulose extraction yield increased with the severity level and treatment duration. The average molecular weight of the extracted hemicellulose macromolecules decreased from $\mathrm{H} 1-60 \%$ ethanol hemicellulose sub-fraction with $143790 \mathrm{~g} / \mathrm{mol}$, followed by H3-60\% ethanol hemicellulose sub-fraction with $110841 \mathrm{~g} / \mathrm{mol}$ and finally H2-60\% ethanol hemicellulose sub-fraction with $61404 \mathrm{~g} / \mathrm{mol}$. The H1-60\% ethanol hemicellulose sub-fraction extracted during the steam explosion at the lowest severity level showed the largest molecular weight and exhibited rather a high arabinose/xylose ratio and uronic acid content. Structural analysis revealed that hemicellulose from the $60 \%$-ethanol hemicellulose sub-fractions were mainly arabino-glucuronoxylan (AGX). However, chemical analysis also revealed significant contents of co-extracted residual lignin. Although the ethanol fractionation helped at lowering the lignin content in the $60 \%$-ethanol hemicellulose sub-fractions (20.1\% in $\mathrm{H} 2-60 \%, 24.0 \%$ in $\mathrm{H} 1-60 \%$ and 28.0 in $\mathrm{H} 3-60 \%$ ) relatively to $80 \%$-ethanol hemicellulose sub-fractions, additional purification step was still required to improve the quality of the extracted hemicellulose sub-fractions (purity and coloration). Nevertheless these results proved that steam explosion was an effective technique for the extraction of high molecular mass AGX hemicellulose macromolecules from banana rachis residues.
\end{abstract}

Keywords Banana rachis $\cdot$ Steam explosion $\cdot$ Hemicellulose $\cdot$ Ethanol fractionation $\cdot$ AGX

Mathias Florian Tiappi Deumaga

mftiappi@student.ulg.ac.be

1 Unit of Industrial Biological Chemistry, Chemistry and Bio-industries, Gembloux Agro Bio-Tech, University of Liège, Passage des Déportés 2, 5030 Gembloux, Belgium

2 Post Harvest Technology Laboratory, African Research Centre on Bananas and Plantains (CARBAP), Njombé, P. O. Box 832, Douala, Cameroon

3 Laboratory of Bioengineering, Earth and Life Institute-Applied Microbiology, Université Catholique de Louvain, Croix du Sud, 2 - L7.05.19, 1348 Louvain-la-Neuve, Belgium

4 Laboratory of Molecular Biophysics at Interfaces, Gembloux Agro-Bio Tech, Passage des Déportés 2, 5030 Gembloux, Belgium

5 Walhain, Belgium

\section{Statement of Novelty}

The valorization of the green residues from agro-industries is a real opportunity for the tropical countries practicing an intensive agriculture of the cash crops. The extraction of biomolecules of interest from agro-industrial biomass could contribute to the local economy of the countries as well as the protection of the environment. In this article, the hemicellulose from banana rachis was extracted for the first time and analyzed by several physico-chemical techniques. The paper also highlights the steam explosion as an chemical free hemicellulose extraction technique. Finally, this article demonstrated that the ethanol fractionation of the extracted hemicellulose helped at obtaining a hemicellulose sub-fraction with a lower content of co-extracted lignin residues. 


\section{Introduction}

Agro-industrial wastes have gained interest worldwide as low cost biomass feedstock. In the banana industry, large quantities of green residues (leaves, hemp, corm, peels and rachis) are generated and represent about $80 \%$ of a banana tree wet mass [1]. Banana rachis represents $6 \%$ of the wet residues and can be easily collected after the packaging of banana fruit. In the literature, banana residues are valorized mainly as biomaterials, heating materials, organic fertilizer (compost) or as animal feeding [2-4]. However, research initiatives for valorization into higher valueadded applications are scarce. The chemical compositions analysis of banana residues have revealed that they contain significant cellulose and hemicellulose sub-fractions [2, 5-7]. Hemicellulose are the second most abundant heteropolymer for vegetal bio-resources after cellulose [8] and represents about $20-30 \%$ of annual and perennial plants biomass [9]. Several hemicellulose extraction techniques are described in the literature. Chemical extraction methods includes alkaline extraction [8, 10-12], soluble acid extraction [13,14] and ionic liquid extraction [15-17]. To avoid the subsequent purification steps that may be required after a chemical extraction, few physical extraction methods such as microwave heating [18], ultrasounds treatment $[19,20]$ and steam treatment [21-25] have been developed. Steam explosion is a thermo-mechanic process [26] generally applied as a pretreatment technique of biomass. It combines a partial extraction of hemicellulose and lignin by an auto-hydrolysis reaction initiated during the treatment, along with a physical destruction of the biomass cell wall induced by the explosive decompression [27]. Moreover, the severity factor of a steam explosion treatment could be defined by adjusting the treatment duration and temperature inside the treatment reactor.

In this research, steam-explosion was assessed as an extraction method of hemicellulose from crude banana rachis (Grande naine). Three different severity levels were defined for the extraction treatments. The extracted hemicellulose were finally fractionated with ethanol and analyzed for their chemical composition and structural features.

\section{Materials and Methods}

\section{Plant Material}

Banana rachis residues were collected from an industrial farm in Cameroon (Central Africa). Before treatment, fresh banana rachis were chopped, air dried until constant mass and coarsely grinded.

\section{Steam Explosion Treatments}

All the treatments were realized with a pilot-scale $50 \mathrm{~L}$ steam explosion reactor [26]. Each treatment was characterized by a severity factor (SF) which was a combination between temperature of the biomass mixture inside the reactor and the treatment duration after the targeted temperature is reached and before the explosion. The calculation formula of the severity factor was formerly developed by Chornet and Overend in 1987 [28]. That formula was improved by Jacquet et al. [26] by considering the duration necessary for the steam explosion reactor to reach the target temperature as this could be significant when a large vessel is used:

$$
\begin{aligned}
\mathrm{SF}= & \log _{10} \sum 14.75 \frac{\mathrm{t}_{\mathrm{n}+1}-\mathrm{t}_{\mathrm{n}}}{\mathrm{T}_{\mathrm{n}+1}-\mathrm{T}_{\mathrm{n}}}\left[\exp \left(\frac{\mathrm{T}_{\mathrm{n}+1}-100}{14.75}\right)\right. \\
& \left.-\exp \left(\frac{\mathrm{T}_{\mathrm{n}}-100}{14.75}\right)\right]
\end{aligned}
$$

where $t_{n}$ and $t_{n+1}$ are the initial times for increments $n$ and $\mathrm{n}+1$ and $\mathrm{T}_{\mathrm{n}}$ and $\mathrm{T}_{\mathrm{n}+1}$ are the process temperature for times $t_{n}$ and $t_{n+1}$ respectively. The factor 14.75 is the activation energy value in the conditions where the process kinetic is of first order and obey to Arrhenius law and the factor 100 is the base temperature $\left(\right.$ in ${ }^{\circ} \mathrm{C}$ ) at which the degradation rate is chosen as unity. For each treatment, about $500 \mathrm{~g}$ of banana rachis sample were used and the treatment parameters (maximum pressure and retention time) were adjusted to obtain the desired severity (Table 1). Exploded samples were further cooled and centrifuged to separate the liquid fraction from the solid residue. The recovered steam explosion liquors (SL) were stored in glass bottles at $4{ }^{\circ} \mathrm{C}$ before their analysis and before ethanol fractionation of the extracted hemicellulose.

\section{Ethanol Fractionation}

The extracted hemicellulose was fractionated with a $96 \%$ denaturized ethanol solution (Labconsult, Brussels-Belgium). Steam explosion liquors were adjusted sequentially to $15 \%, 60 \%$ and $80 \%$ ethanol content and the precipitated hemicellulose was recovered by centrifugation ( $8000 \mathrm{rpm}$,

Table 1 Steam explosion treatments operating conditions

\begin{tabular}{llll}
\hline Steam explosion run number & 1 & 2 & 3 \\
\hline $\begin{array}{l}\text { Max temperature }\left({ }^{\circ} \mathrm{C}\right) / \text { pressure } \\
\text { (bars) }\end{array}$ & $201 / 15.47$ & $220 / 22.54$ & $217 / 21.23$ \\
$\begin{array}{l}\text { Total treatment duration (sec- } \\
\text { ond } \times \text { s) }\end{array}$ & 175 & 184 & 300 \\
\begin{tabular}{l} 
Severity factor $(\mathrm{SF})$ \\
\hline
\end{tabular} & 2.97 & 3.57 & 3.78 \\
\hline
\end{tabular}


$5 \mathrm{~min}$ ). The recovered hemicellulose were further rinsed three times with $96 \%$ ethanol and freeze-dried.

The hemicellulose extraction process including steamexplosion treatment and ethanol fractionation is described in Fig. 1.

\section{Chemical Composition Analysis}

Crude banana rachis samples were analyzed for their ash content (TAPPI T211 om-02 method), total proteins content (AOAC 984.13 method) and extractives compounds (water and ethanol) content.

Cellulose and hemicellulose contents were analyzed by Van-Soest's fiber determination technique [29].

Acid insoluble lignin also known as Klason lignin was determined after the two steps hydrolysis method $(1 \mathrm{~h}$ prehydrolysis with $72 \%$ sulfuric acid solution followed by a $1 \mathrm{~h}$ $4 \%$ sulfuric solution treatment) as described by Sluiter et al. [30]. Klason lignin was then calculated as the difference between the dry mass of the solid residue and its ash content.

For neutral sugars quantification in crude banana rachis samples, a modified version of the classical Saeman's hydrolysis and monosaccharides analysis procedure was used [31]: $300 \mathrm{mg}$ of dried samples were submitted to $1 \mathrm{~h}$ pre-hydrolysis treatment at $30{ }^{\circ} \mathrm{C}$ with $72 \% \mathrm{H}_{2} \mathrm{SO}_{4}$, followed by dilution to $4 \% \mathrm{H}_{2} \mathrm{SO}_{4}$ and $1 \mathrm{~h}$ hydrolysis treatment at $121{ }^{\circ} \mathrm{C}$. For neutral sugars quantification in hemicellulose sub-fractions, $5 \mathrm{mg}$ of each sample were hydrolyzed by $5 \mathrm{ml}$ of $6 \% \mathrm{H}_{2} \mathrm{SO}_{4}$ for $6 \mathrm{~h}$ at $105^{\circ} \mathrm{C}$.

After each of the above hydrolysis treatment, the released monosaccharides were further derivatized into alditol acetates and quantified by gas chromatography equipped with a flame ionization detector (GC-FID, Hewlett-Packard Co./Column: HP1-methylsiloxane $30 \mathrm{~m}$ length/0.32 mm

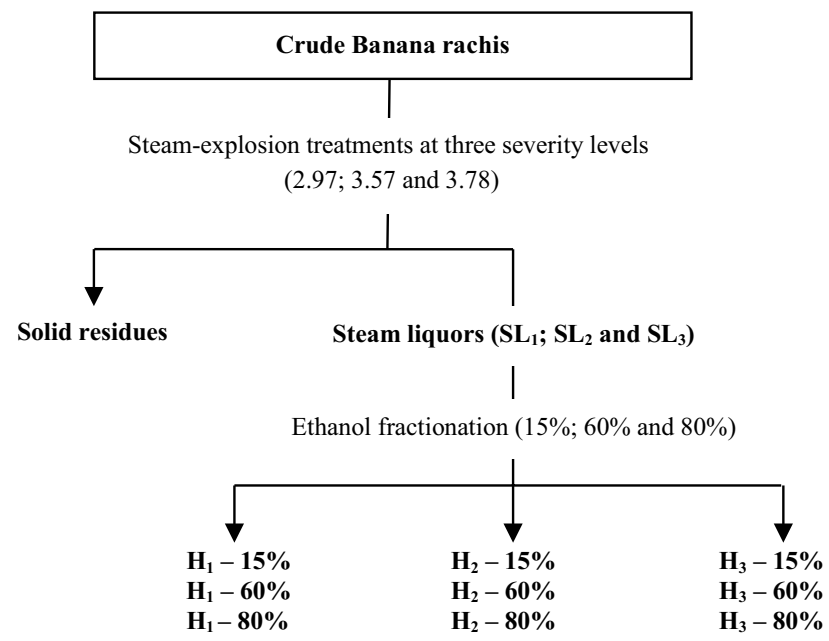

Fig. 1 Extraction and fractionation process of hemicelluloses from banana rachis by steam explosion diameter/0.25 $\mu \mathrm{m}$ film thickness, Scientific Glass Engineering, S.G.E. Pty. Ltd., Melbourne, Australia). A mixture of six monosaccharides (glucose, xylose, arabinose, rhamnose, mannose, galactose) of known concentration was treated in the same conditions as described above and used as calibration solution.

Concentration in 5-hydroxymethyl furfural (5-HMF) in steam explosion liquor was determined by liquid chromatography as described by Jacquet et al. [26]. A HPLC-DAD was used (Waters 2690 Separation Module, column Agilent Zorbax 300SB-C18, 4.6×150, equipped with a Waters 996 Photodiode Array Detector) and a 5-HMF standard solution (Acros organic, ref. 121460010) was used as calibration solution.

Uronic acid content in hemicellulose sub-fractions was determined by high performance anion-exchange chromatography with a pulsed amperometric detector (HPAECPAD, Dionex, Sunnyvale, USA) equipped with a Carbopac PA100 column $(4 \times 250 \mathrm{~mm})$ in combination with a Carbopac PA100 guard column $(4 \times 50 \mathrm{~mm})$. Hemicellulose samples were submitted to a two-step sulfuric acid hydrolysis ( $1 \mathrm{~h}$ pre-hydrolysis with $72 \% \mathrm{H}_{2} \mathrm{SO}_{4}$ solution at ambient temperature followed by a $6 \mathrm{~h}$ hydrolysis with $1 \mathrm{M} \mathrm{H}_{2} \mathrm{SO}_{4}$ at $105{ }^{\circ} \mathrm{C}$ ). A standard glucuronic solution was used as calibration solution.

\section{Thermogravimetry Analysis}

Thermogravimetric (TGA) analyses were performed with a TGA/DSC1 instrument (Mettler-Toledo, Greifensee, Switzerland). The pyrolysis was conducted under a nitrogen flow of $50 \mathrm{ml} / \mathrm{min}$. The experiments were conducted in triplicate using $70 \mu \mathrm{l}$ alumina pans. For each assay, $10 \mathrm{mg}$ of each sample was used. Thermo-degradations were performed over a temperature range from 30 to $600{ }^{\circ} \mathrm{C}$ at a heating rate of $20{ }^{\circ} \mathrm{C} / \mathrm{min}$.

\section{Molecular Mass Distribution Analysis}

Molecular mass distribution of the extracted hemicellulose sub-fractions was determined by Gel Permeation Chromatography [GPC, Agilent Technologies, 1200 series, equipped with Multi-Angles Light Scattering (MALS) and Refraction Index detectors (RI)]. Calibration was realized with Dextran standards with molecular weights varying from 80 to $1300 \mathrm{kDa}$.

\section{FTIR, Proton and 2D-HSQC NMR Structural Analysis}

About $5 \mathrm{mg}$ of the extracted hemicellulose samples (lyophilized) were mixed with potassium bromide in a ratio of $1 / 100$ and then mechanically pressed in order to form a 
pellet. The pellets were then subjected to infrared spectroscopy analysis and the FTIR spectra were recorded in the $2000-400 / \mathrm{cm}$ range with 16 scans at a resolution of $4 / \mathrm{cm}$ on a Bruker IFS 48 spectrometer.

NMR analyses were performed using a Varian Unity $600 \mathrm{MHz}$ instrument at $298 \mathrm{~K}$. For the ${ }^{1} \mathrm{H}$ NMR analysis $\left(45^{\circ}\right.$ pulse angle $/ 3.98 \mathrm{~s}$ acquisition time $/ 1 \mathrm{~s}$ relaxation delay/128 repetitions) about $20 \mathrm{mg}$ of each hemicellulose samples was dissolved in $1 \mathrm{ml}$ of $\mathrm{D}_{2} \mathrm{O}$. For the ${ }^{1} \mathrm{H}_{-}{ }^{13} \mathrm{C}$ 2D-Heteronuclear Single Quantum Coherence NMR analysis $(0.213 \mathrm{~s}$ acquisition time $/ 5 \mathrm{~s}$ relaxation delay/32 repetitions $/ 2 \times 256$ increments), around $80 \mathrm{mg}$ were dissolved in $1 \mathrm{ml}$ of $\mathrm{D}_{2} \mathrm{O}$ and mixed during $24 \mathrm{~h}$ at ambient temperature and analysis were performed in $5 \mathrm{~mm}$ Shigemi NMR micro-tubes.

\section{Results and Discussion}

\section{Banana Rachis Chemical Composition}

The chemical composition of banana rachis from Grande naine variety (Musa cavendish) is given in Table 2. The major components were cellulose, hemicellulose and ash.

The ash content (28.5\%) was slightly higher than observations made by Oliveira et al. [6] in banana rachis from Dwarf Cavendish variety (26.8\%). The inorganic compounds such as potassium $(\mathrm{K})$ which is the main compound in banana rachis ash [5] could have an important influence during the steam pretreatment process as they can buffer the autohydrolysis processes [32, 33].

Table 2 Chemical composition of crude dried rachis from Grande naine (Musa spp.) banana variety

\begin{tabular}{lc}
\hline Chemical component & $\begin{array}{l}\%(w / w) \text { in } \\
\text { crude mate- } \\
\text { rial }\end{array}$ \\
\hline Total ash & 28.5 \\
Total proteins & 4.3 \\
Extractives $^{\mathrm{a}}$ (water and ethanol) & 9.7 \\
Cellulose (Van Soest) & 35.3 \\
Hemicelluloses (Van Soest) & 17.9 \\
Acid insoluble lignin (Klason) & 6.0 \\
Monosaccharides relative composition (\% total sugars) & \\
Glucose & 78.3 \\
Xylose & 13.4 \\
Arabinose & 4.1 \\
Mannose & 2.1 \\
Galactose & 1.6 \\
Rhamnose & 0.3 \\
\hline
\end{tabular}

${ }^{\mathrm{a}}$ Value corrected from extracted ash and proteins
The relative content in hemicellulose (17.9\%) was found to be lower than the average contents in other herbaceous biomass feedstock: $20-39 \%$ are found in wheat straw [34, 35 ] or 24-36\% in miscanthus [36-38]. However the banana rachis hemicellulose content was still significant and can therefore be valorized.

The relative content in neutral monosaccharides (glucose $78.3 \%$; xylose $13.4 \%$; arabinose $4.1 \%$; mannose $2.1 \%$; galactose $1.6 \%$; rhamnose $0.3 \%$ ) were similar to observations made for banana rachis from Dwarf Cavendish by Oliveira et al. [6].

\section{Chemical Composition of Liquors from Steam-Explosion}

Chemical composition of steam explosion liquor is reported in Table 3. For each treatment, concentrations in 5-HMF increased with severity level. However, concentrations were still minor even at maximal severity treatment $(<10 \mathrm{ppm})$. In fact, Jacquet et al. [26] reported for microcrystalline cellulose that sugar degradation products (5-HMF and $2 \mathrm{~F}$ ) during steam explosion treatments occurred only with severity factors above 4.0, after which an exponential increase of 5 -HMF was observed.

Regarding the relative composition in neutral monosaccharides, the major components were xylose (28.5-37.4\%), arabinose (34.6-35.9\%) and glucose (11.4-17.2\%) and they were suggested to be released by solubilization of hemicellulose and amorphous cellulose fraction from banana rachis.

\section{Fractionation of Extracted Hemicellulose}

An accurate calculation of hemicellulose extraction yields from initial crude banana rachis samples was impossible because of the significant material losses inside the explosion vessel. Total precipitation yields were therefore expressed relatively to the steam explosion liquors dry weight (Table 4).

Table 3 Chemical composition of steam explosion liquors (SL) from banana rachis steam explosion treatment

\begin{tabular}{lccc}
\hline & $\mathrm{SL}_{1}$ & $\mathrm{SL}_{2}$ & $\mathrm{SL}_{3}$ \\
\hline Severity factor (SF) & 2.97 & 3.57 & 3.78 \\
5-HMF (ppm) & 7.1 & 8.7 & 9.3 \\
Relative composition in neutral monosaccharides (\%) & \\
Arabinose & 34.8 & 34.6 & 35.9 \\
Xylose & 28.5 & 35.9 & 37.4 \\
Glucose & 17.2 & 11.4 & 12.5 \\
Galactose & 14.9 & 10.6 & 11.5 \\
Rhamnose & 4.4 & 4.6 & 1.7 \\
Mannose & 0.2 & 2.9 & 1.0 \\
\hline
\end{tabular}


An increase in the total extraction yields was observed in relation with the increasing severity factor, with a particularly high value found in $\mathrm{SL}_{3}$ fraction. The same observation was made by García-Aparicio et al. [33] who noticed a decrease of insoluble solids recovered from steam-exploded Giant Bamboo with an increasing severity factor.

The relative precipitation yields from ethanol fractionation of steam liquors (SL) are also reported in Table 4. The $15 \%$ ethanol hemicellulose precipitation yields $\left[\mathrm{SL}_{1}\right.$ (10.3\%), $\mathrm{SL}_{2}(5.3 \%)$ and $\mathrm{SL}_{3}(3.4 \%)$ ] were relatively low in comparison to $60 \%$ and $80 \%$ ethanol precipitation yields, and were not considered for further analyses. From a global point of view, maximum precipitation yields were observed for $60 \%$ ethanol sub-fractions in $\mathrm{SL}_{1}$ and $\mathrm{SL}_{3}(69.0 \%$ and $81.4 \%$ respectively) while for $\mathrm{SL}_{2}$, the precipitation yield at $80 \%$ ethanol concentration (55.3\%) was the highest.

\section{Molecular Mass Distribution and Chemical Composition of Hemicellulose Sub-fractions}

Higher molecular mass were globally observed in $60 \%$ ethanol hemicellulose sub-fractions (Table 5): $143790 \mathrm{~g} / \mathrm{mol}$ in $\mathrm{H}_{1}$ followed by $\mathrm{H}_{3}(110841 \mathrm{~g} / \mathrm{mol})$ and $\mathrm{H}_{2}(61404 \mathrm{~g} /$ mol). The high molecular mass observed was assimilated to highly substituted xylopyranosyl backbones based on their arabinose/xylose ratio and uronic acid contents (Table 6). The high arabinose/xylose ratios above 0.5 suggested high hydro-solubility properties [9] of the extracted hemicelluloses. The most substituted macromolecules with greater arabinose/xylose ratio and greater contents in uronic acids were found in $\mathrm{H}_{1}$ sub-fractions obtained by steam explosion treatment with the lowest severity factor (lowest maximum temperature and shorter treatment duration). Water-soluble hemicellulose are interesting for some rheological applications as they show a shear-thinning behavior (decrease of
Table 4 Yields of ethanol fractionation $(15 \%, 60 \%$ and $80 \%$ ethanol) of extracted hemicellulose from steam explosion liquors (SL)
Table 5 Weight-average $(\mathrm{Mw})$ and number-average (Mn) molecular weights and polydispersity (Mw/Mn) of the $60 \%$ and $80 \%$ ethanol hemicellulose sub-fractions
Table 6 Total neutral sugars, neutral monosaccharides (rel. $\%$ ), uronic acids (\% DM) and Klason lignin (\% DM) contents in $60 \%$ and $80 \%$ ethanol hemicellulose sub-fractions

\begin{tabular}{llllllllll}
\hline & $\mathrm{SL}_{1}$ & & & $\mathrm{SL}_{2}$ & \multicolumn{5}{c}{$\mathrm{SL}_{3}$} \\
\hline Severity factor (SF) & 2.97 & & & 3.57 & & & 3.78 & & \\
Ethanol percentage & $15 \%$ & $60 \%$ & $80 \%$ & $15 \%$ & $60 \%$ & $80 \%$ & $15 \%$ & $60 \%$ & $80 \%$ \\
Total yield (\% dry weight) & 41.7 & & & 42.3 & & & 70.4 & & \\
Relative yield (\%) & 10.3 & 69.0 & 20.7 & 5.3 & 39.4 & 55.3 & 3.4 & 81.4 & 15.2 \\
\hline
\end{tabular}

\begin{tabular}{lllllll}
\hline & $\mathrm{H}_{1}$ & & $\mathrm{H}_{2}$ & & $\mathrm{H}_{3}$ & \\
\hline Severity factor (SF) & 2.97 & & 3.57 & & 3.78 & \\
Ethanol percentage & $60 \%$ & $80 \%$ & $60 \%$ & $80 \%$ & $60 \%$ & $80 \%$ \\
Mw (g/mol) & 143790 & 35156 & 61404 & 14405 & 110841 & 20569 \\
Mn (g/mol) & 22021 & 14542 & 13488 & 8007 & 18747 & 9182 \\
Mw/Mn & 6.5 & 2.4 & 4.5 & 1.8 & 5.9 & 2.2 \\
\hline
\end{tabular}

\begin{tabular}{lllllll}
\hline & $\mathrm{H}_{1}$ & & $\mathrm{H}_{2}$ & & $\mathrm{H}_{3}$ & \\
\hline Severity factor (SF) & 2.97 & & 3.57 & & 3.78 & \\
Ethanol percentage & $60 \%$ & $80 \%$ & $60 \%$ & $80 \%$ & $60 \%$ & $80 \%$ \\
Uronic acid (\% DW) & 3.5 & 1.2 & 0.9 & 1.0 & 0.7 & 0.8 \\
Klason lignin (\% DW) & 24.0 & 74.1 & 20.1 & 63.2 & 28.0 & 68.5 \\
Total neutral sugars (\% DW) & 40.1 & 15.0 & 57.2 & 18.9 & 47.9 & 17.5 \\
Relative composition in neutral sugars (\% DW) & & & & & \\
Xylose & 39.0 & 22.7 & 45.1 & 36.1 & 40.8 & 40.6 \\
Arabinose & 39.6 & 27.0 & 32.7 & 30 & 36.1 & 33.7 \\
Glucose & 4.2 & 7.2 & 7.3 & 5.9 & 5.5 & 6.4 \\
Galactose & 14.0 & 22.4 & 13.2 & 22.0 & 17.6 & 19.3 \\
Rhamnose & 3.1 & 14.5 & $\mathrm{nd}^{\mathrm{a}}$ & 3.8 & $\mathrm{nd}^{\mathrm{a}}$ & $\mathrm{nd}^{\mathrm{a}}$ \\
Mannose & $\mathrm{nd}$ & 6.2 & 1.7 & 2.1 & $\mathrm{nd}^{\mathrm{a}}$ & $\mathrm{nd}^{\mathrm{a}}$ \\
Ara/Xyl & 1.0 & 1.2 & 0.5 & 0.8 & 0.9 & 0.8 \\
\hline
\end{tabular}

${ }^{\mathrm{a}}$ Not detected (below detection limit) 
solution viscosity with increasing shear stress during agitation) without thixotropy (no return to initial viscosity) in solution [39].

According the results described above, it seems that two phenomena occurred during the steam explosion treatment: At first, an extraction of polysaccharide macromolecules took place, and was then followed by a de-polymerization process of extracted macromolecules into lower molecular mass molecules. The decrease in molecular weight observed for the $60 \%$ ethanol hemicellulose between $\mathrm{H}_{1}$ and $\mathrm{H}_{2}$ subfractions can be attributed to the predominance of de-polymerization reactions over extraction of hemicellulose macromolecules. This hypothesis is confirmed by the decrease in the arabinose/xylose ratio from 1.0 to 0.5 observed for the same hemicellulose sub-fractions (see Table 6) and also by the decrease of the polydispersity index $(\mathrm{Mw} / \mathrm{Mn})$ from 6.5 to 4.5 (Table 5). This phenomenon also resulted in a decrease of the relative yield for the $60 \%$ ethanol $\mathrm{H}_{2}$ subfraction from 69.0 to $39.4 \%$ (Table 4). Similar observation was made by Bian et al. [40] who noticed a decrease in $\mathrm{Mw}$ and polydispersity index for alkali extraction of hemicellulose from sugarcane bagasse for treatment temperature above $40{ }^{\circ} \mathrm{C}$.

Furthermore, the increase of the molecular weight oh $\mathrm{H}_{3}-60 \%$ ethanol hemicellulose sub-fraction relatively to $\mathrm{H}_{2}-60 \%$ can be attributed to the increase of treatment severity which allowed a reverse behavior with a predominance of extraction of hemicellulose macromolecules over de-polymerization reactions. This resulted in an increase of both polydispersity index (5.9) and arabinose/xylose ratio (0.9).

The molecular mass of the $60 \%$ ethanol hemicellulose sub-fractions were globally higher than alkali-extracted hemicellulose in the literature $(16,000-93,000 \mathrm{~g} / \mathrm{mol})[8$, $10-12,40,41]$.

The total neutral sugar contents and the relative monosaccharides distribution of the different hemicellulose subfractions are also given in Table 6. The recovered hemicellulose at $60 \%$ ethanol fractionation showed the highest yield in neutral sugars. $\mathrm{H}_{2}-60 \%$ hemicellulose sub-fraction was the highest (57.2\%) in neutral sugars content, followed by $\mathrm{H}_{3}-60 \%$ (47.9\%) and $\mathrm{H}_{1}-60 \%$ (40.1\%) sub-fractions. In all hemicellulose sub-fractions, the main monosaccharides were found to be xylose, arabinose, galactose and glucose respectively.

Regarding the $80 \%$ ethanol hemicellulose sub-fractions, it was noticed that lignin was the main component with $74.1 \%$ Klason lignin in $\mathrm{H}_{1}-80 \%, 63.2 \%$ in $\mathrm{H}_{2}-80 \%$ and $68.5 \%$ in $\mathrm{H}_{3}-80 \%$. Klason lignin contents in $60 \%$ ethanol hemicellulose sub-fractions were also significant (20-28\%). The high lignin content was assimilated to condensed or re-polymerized lignin residues co-extracted with hemicellulose during steam explosion treatment. Several techniques are reported to reduce lignin content such as alkaline peroxide treatment in order to improve hemicellulose quality and coloration [23, $41,42]$.

\section{Thermogravimetric Analysis}

Thermogravimetric analysis curves are provided in Fig. 2 . Three main pyrolysis phases were identified: the first one started from about $40-170{ }^{\circ} \mathrm{C}$ and was assimilated to the dehydration of the hemicellulose sub-fractions. The second stage ranged from 170 to $370{ }^{\circ} \mathrm{C}$ and was assimilated to hemicellulose polymers fragmentation and decomposition
Fig. 2 TGA and DTG curves of $60 \%$-ethanol hemicelluloses sub-fractions $\mathrm{H}_{1}, \mathrm{H}_{2}$ and $\mathrm{H}_{3}$

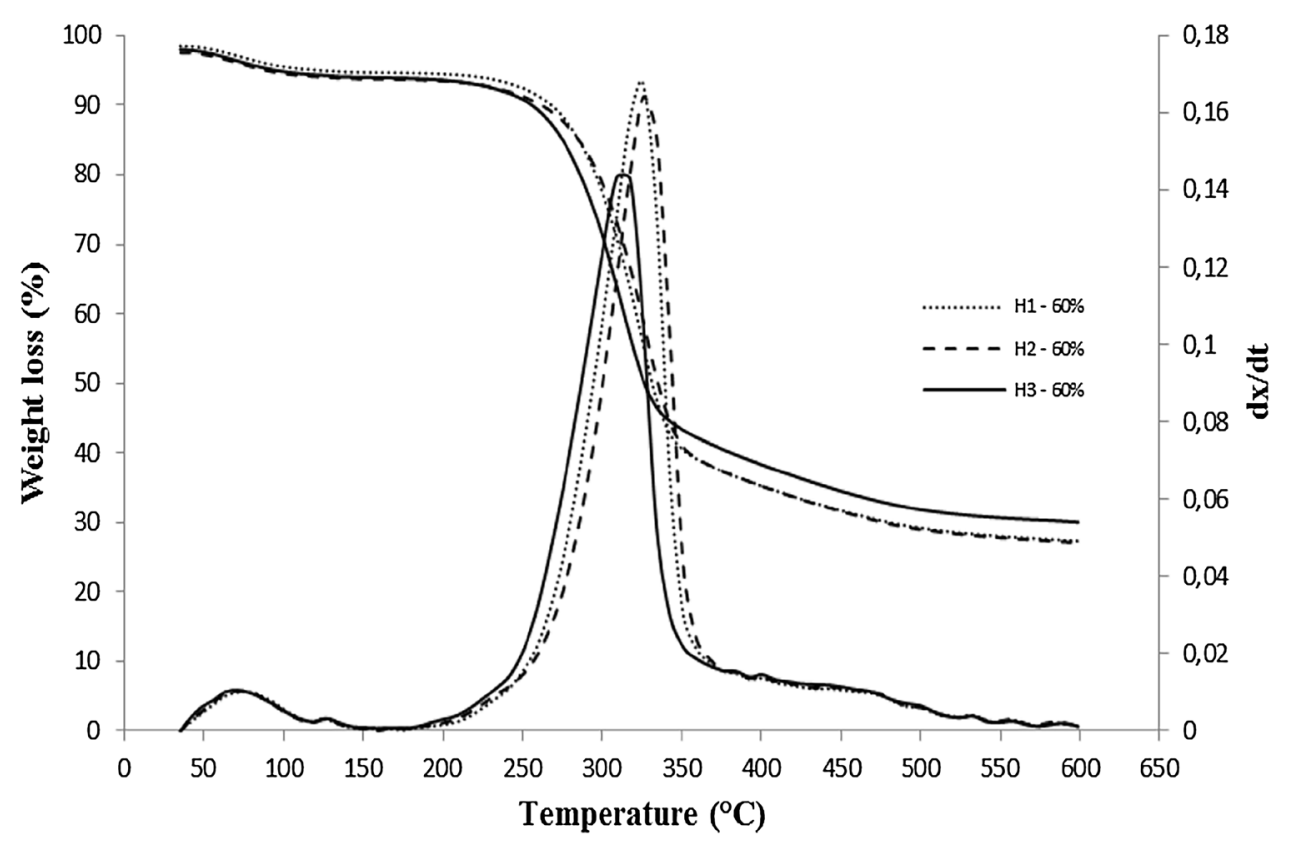


into smaller molecules like $\mathrm{CO}, \mathrm{CO}_{2}, \mathrm{CH}_{4}, \mathrm{CH}_{3} \mathrm{COOH}$ and $\mathrm{HCOOH}$ as suggested by Bian et al. [40]. The final stage from 370 to $520^{\circ} \mathrm{C}$ was suggested to be the terminal degradation of residual lignin and char formation (27-30\%). The slight shift between the TGA/DTG curves could be due to lignin contribution during the early degradation stages. Curves shifts were aligned with decreasing content in Klason lignin from $\mathrm{H}_{3}$ hemicellulose sub-fractions (28.0\%), followed by $\mathrm{H}_{1}(24.0 \%)$ and $\mathrm{H}_{2}(20.1 \%)$.

\section{FT-IR Spectroscopy Analysis}

The FT-IR spectra of the $60 \%$ ethanol hemicellulose subfractions are shown in Fig. 3. The hemicellulose fingerprint region were found between 1800 and $800 / \mathrm{cm}$ [40]. The intensive band found at $1047 / \mathrm{cm}$ was assigned to $\mathrm{C}-\mathrm{O}$ and $\mathrm{C}-\mathrm{C}$ links stretching and to $\mathrm{C}-\mathrm{O}-\mathrm{C}$ glycosidic links contribution of xylan backbone. Sun et al. [43] also reported that bands between 1152 and $995 / \mathrm{cm}$ were typical of arabinoxylan. The small peak at $906 / \mathrm{cm}$ was indicative of the $\beta$-configuration of the $1 \rightarrow 4$ xylopyranosyl linkages [40]. The signal at $1081 / \mathrm{cm}$ was related to the $\mathrm{C}-\mathrm{OH}$ links bending which is strongly influenced by the derivatization degree of the hemicellulose macromolecule [11]. The signal at $1155 / \mathrm{cm}$ was characteristic of arabinofuranosyl (Araf) linkages. Signals at 1320 and 1247/cm were assigned to $-\mathrm{CH}$ stretching, $-\mathrm{OH}$ or $\mathrm{C}-\mathrm{O}$ bending in hemicellulose [40] like in carboxylic acid vibration due to 4-O-Methyl- $\alpha$ D-glucuronic acids groups [8]. Signal at $1508 / \mathrm{cm}$ found by Xue et al. [8] is characteristic of residual bounded lignin and seemed to be overlapped with adsorbed water signal and some other signals in our experiments. From a global consideration, the FT-IR spectrum profiles of the analyzed hemicellulose sub-fractions were similar and confirmed their arabino-glucuronoxylan (AGX) structure.

\section{NMR Analysis}

${ }^{1} \mathrm{H}$ NMR spectra of the hemicellulose sub-fractions isolated at $60 \%$ ethanol are shown in Fig. 4. Relevant signals from hemicellulose generally occurred in two main regions, namely the anomeric region at $\delta 4.90-4.30 \mathrm{ppm}$ and the ring protons region at $\delta 4.50-3.00 \mathrm{ppm}$ [8]. The strongest signal at $4.70 \mathrm{ppm}$ was assigned to solvent $\left(\mathrm{D}_{2} \mathrm{O}\right)$. In the anomeric region, signals at 5.33 and $5.27 \mathrm{ppm}$ were assimilated to terminal $\alpha$-arabinose residues linked to $\mathrm{O}-3$ and $\mathrm{O}-2$ respectively. This was confirmed by the signal at $4.57 \mathrm{ppm}$ corresponding to $\beta$-D-xylose substituted at C-3 position [10]. For the $\mathrm{H}_{1}$ hemicellulose sub-fraction, signal in the anomeric region were broader and more intense, and overlapping with the $\mathrm{D}_{2} \mathrm{O}$ peak. This could be explained by the highest arabinose/xylose ratio found for this fraction (Table 6). In the ring protons region, characteristic signals of $\mathrm{H}-3, \mathrm{H}-4$ and $\mathrm{H}-5_{\mathrm{eq} / \mathrm{ax}}$ protons were found at 3.51, 3.69, and 4.08-3.31 ppm respectively and the methyl proton of 4- $O$-Methyl-D-glucuronic acid was found at $3.43 \mathrm{ppm}$ [44]. The sharp signal at $2.21 \mathrm{ppm}$ was assigned to acetyl group of the different acetylated polysaccharides [8]. Apart some slight differences, spectra were very similar and in accordance with an AGX structure. This similarity was also confirmed by the ${ }^{1} \mathrm{H} /{ }^{13} \mathrm{C}$ HSQC NMR spectra (Fig. 5). Only signals between 3.1 and $4.5 \mathrm{ppm}$ in the proton dimension were represented as they are characteristic of arabinose and xylose residues [44]. Chemical shift of H-3/C-3, H-4/ $\mathrm{C}-4$ and $\mathrm{H}-5 / \mathrm{C}-5$ from the $(1 \rightarrow 4)-\beta$-D-Xyl $p$ backbone (A) were found respectively at $\delta_{\mathrm{H}} / \delta_{\mathrm{C}} 3.62 / 75.9,3.54 / 75.0$ and 3.34/63.2 [8]. The presence of the $\alpha$-L-Araf residues (D)
Fig. 3 FTIR spectra of $60 \%$-ethanol hemicelluloses sub-fractions $\mathrm{H}_{1}, \mathrm{H}_{2}$ and $\mathrm{H}_{3}$

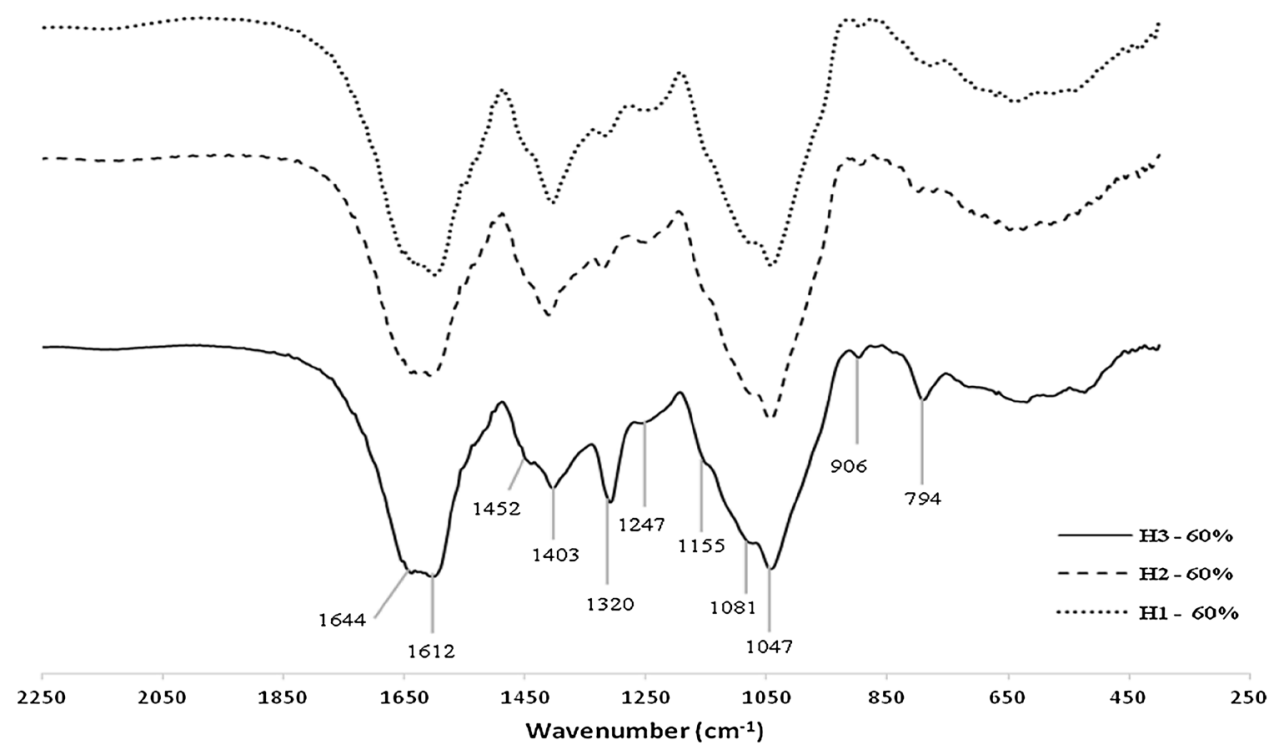


Fig. 4 Proton NMR spectrum of $60 \%$-ethanol hemicelluloses sub-fractions $\mathrm{H}_{1}, \mathrm{H}_{2}$ and $\mathrm{H}_{3}$



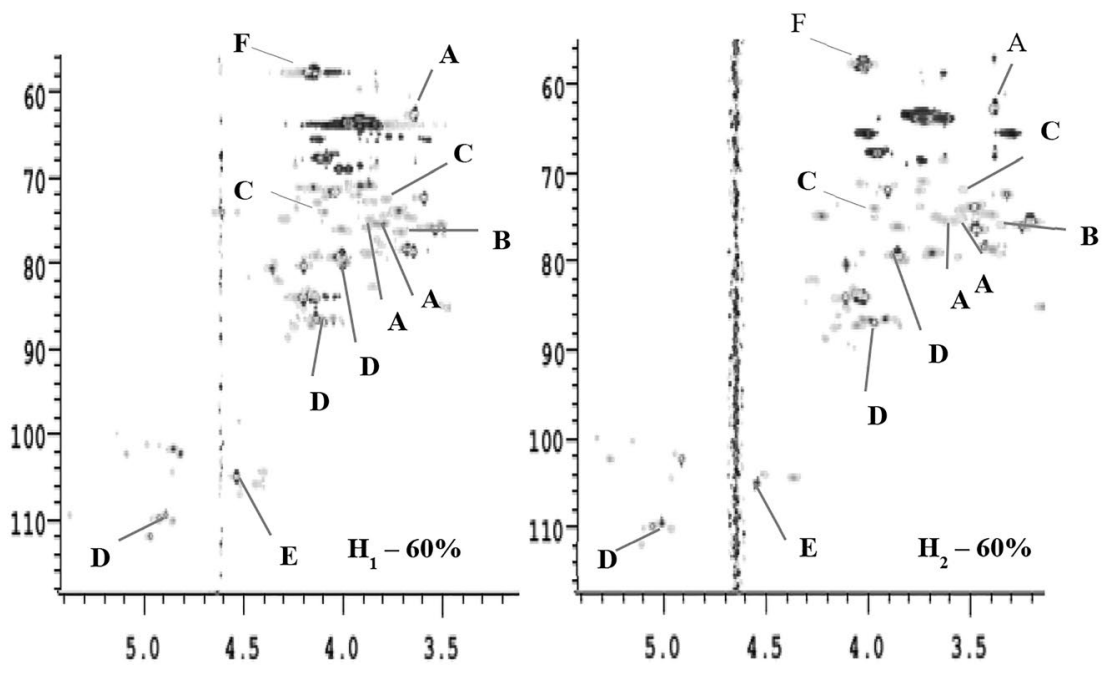

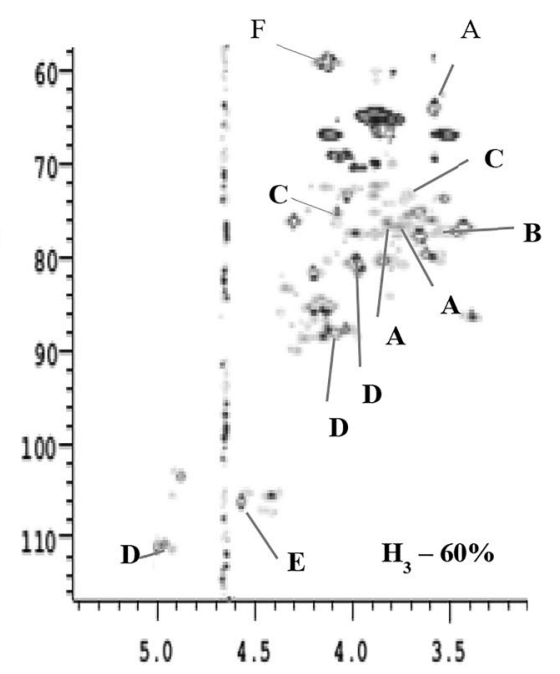

Fig. 5 HSQC NMR spectra of $60 \%$-ethanol hemicelluloses sub-fractions $\mathrm{H}_{1}, \mathrm{H}_{2}$ and $\mathrm{H}_{3}$. A: $(1 \rightarrow 4)-\beta$-D-Xyl $p$; B: $(1 \rightarrow 4)-\beta$-D-Xylp-2-O-(4OMe- $\alpha$-D-GlcpA); C: $\alpha$-L-Araf; D: $\alpha$-L-Araf; E: $(1 \rightarrow 6)-\alpha-\mathrm{D}-\mathrm{Gal} p$; F: Lignin-OCH

was also confirmed by the chemical shift at 5.06/110.2, $3.83 / 79.96$ and 3.95/87.35 corresponding to the H-1/C-1, $\mathrm{H}-2 / \mathrm{C}-2$ and $\mathrm{H}-4 / \mathrm{C}-4$ respectively. Residues of $4-\mathrm{OMe}-\alpha-$ D-Glucuronopyranosyl acetate $(\mathrm{C})$ were identified by the chemical shift of their $\mathrm{H}-2 / \mathrm{C}-2$ and $\mathrm{H}-3 / \mathrm{C}-3$ at 3.50/72.0 and 3.88/72.6 respectively. A signal was also detected at $\delta 3.44 / 76.74$ characteristic of $\mathrm{H}-2 / \mathrm{C}-2$ involved in $(1 \rightarrow$ 4)- $\beta$-D-Xyl $p$-2-O-(4-OMe- $\alpha$-D-Glc $p \mathrm{~A})$ linkage. Because of the significant content in galactose as shown in neutral sugar analysis, chemical shift of $(1 \rightarrow 6)-\alpha-D-G a l p$ residue (E) was detected at $\delta 4.54 / 105.37$ in all the spectra. Finally, a strong signal at $\delta 4.00 / 58.4$ was identified as from the lignin- $\mathrm{OCH}_{3}$ residues (F) confirming the presence of a significant content in lignin residues.

\section{Conclusion}

Steam explosion of banana rachis and ethanol fractionation (15\%, 60\% and 80\%) allowed the extraction and separation of hemicellulose sub-fractions with specific characteristics. An increase of the extraction yield along with the increasing severity of the steam explosion treatment was observed. During the ethanol fractionation, the relative yields at 
$15 \%$ ethanol were globally the lowest highest yields were obtained for the $60 \%$ ethanol hemicellulose sub-fractions. The molecular weight of the extracted hemicellulose macromolecules ranged from $143790 \mathrm{~g} / \mathrm{mol}$ for $\mathrm{H}_{1}-60 \%$ followed by the $\mathrm{H}_{3}-60 \%$ (110 $841 \mathrm{~g} / \mathrm{mol}$ ) and finally $\mathrm{H}_{2}-60 \%$ (61 $404 \mathrm{~g} / \mathrm{mol})$. The molecular distribution was found to be influenced by the competition between extraction reactions of large hemicellulose macromolecules from crude banana rachis and their hydrolysis during treatment according to the severity. The structural analysis by FTIR, ${ }^{1} \mathrm{H}$ and ${ }^{1} \mathrm{H} /{ }^{13} \mathrm{C}$ HSQC NMR revealed that the hemicellulose from the $60 \%$ ethanol fractionation had an AGX structure. This was also confirmed by neutral sugar analysis, where xylose and arabinose were the main monosaccharides with significant amounts of uronic acid. However, Klason lignin analysis of the extracted hemicelluloses sub-fractions revealed significant contents in lignin residues co-extracted during the steam explosion treatment. The ethanol fractionation helped to lower lignin content in $60 \%$ hemicellulose sub-fraction. Additional purification treatment was still needed though to decrease the lignin content and improve the coloration of the extracted hemicellulose. Nevertheless, these results proved that steam-explosion was an effective technique for hemicellulose extraction from banana rachis.

Acknowledgements Financial support and scholarship for these studies (Project: valorization of banana residues and contribution to local sustainable development) were provided by the Commission Universitaire pour le Développement (CUD) from Belgium. The authors are also grateful to the laboratory of post-harvest technology, CARBAPCameroon and also to the research staff from the Industrial Chemistry and Biology laboratory and Analytical Chemistry Laboratory (GxABTech, ULg, Belgium). Magali DELEU thanks the Fond National de la Recherche Scientifique from Belgium for her position as Research Associate.

\section{References}

1. Gañán, P., Zuluaga, R., Restrepo, A., Labidi, J., Mondragon, I.: Plantain fibre bundles isolated from Colombian agro-industrial residues. Bioresour. Technol. 99, 486-491 (2008). https://doi. org/10.1016/j.biortech.2007.01.012

2. Mohapatra, D., Mishra, S., Sutar, N.: Banana and its by-product utilisation: an overview. J. Sci. Ind. Res. 69, 323-329 (2010)

3. Kamdem, I., Tomekpe, K., Thonart, P.: Production potentielle de bioéthanol, de biométhane et de pellets à partir des déchets de biomasse lignocellulosique du bananier (Musa spp.) au Cameroun. Biotechnol. Agron. Soc. Environ. 15, 471-483 (2011)

4. Kamdem, I., Hiligsmann, S., Vanderghem, C., Jacquet, N., Tiappi, F.M., Richel, A., Jacques, P., Thonart, P.: Enhanced biogas production during anaerobic digestion of steam-pretreated lignocellulosic biomass from williams cavendish banana plants. Waste Biomass Valoriz. (2016). https://doi.org/10.1007/s12649-016-9788-6

5. Tiappi, M.F.D., Emaga, T.H., Tchokouassom, R., Vanderghem, C., Aguedo, M., Gillet, S., Jacquet, N., Danthine, S., Deleu, M., Richel, A.: Genotype contribution to the chemical composition of banana rachis and implications for thermo/biochemical conversion. Biomass Convers. Biorefin. (2015). https://doi. org/10.1007/s13399-015-0158-6

6. Oliveira, L., Cordeiro, N., Evtuguin, D.V., Torres, I.C., Silvestre, A.J.D.: Chemical composition of different morphological parts from "Dwarf Cavendish" banana plant and their potential as a non-wood renewable source of natural products. Ind. Crops Prod. 26, 163-172 (2007). https://doi.org/10.1016/j.inder op.2007.03.002

7. Cordeiro, N., Oliveira, L., Evtuguin, D., Silvestre, A.J.D.: Structural characterization of stalk lignin from banana plant. Ind. Crops Prod. 29, 86-95 (2009). https://doi.org/10.1016/j.inder op.2008.04.012

8. Xue, B.-L., Wen, J.-L., Xu, F., Sun, R.-C.: Structural characterization of hemicelluloses fractionated by graded ethanol precipitation from Pinus yunnanensis. Carbohydr. Res. 352, 159-165 (2012). https://doi.org/10.1016/j.carres.2012.02.004

9. Ebringerova, A.: Structural diversity and application potential of hemicelluloses. Macromol. Symp. 232, 1-12 (2006). https://doi. org/10.1002/masy.200551401

10. Peng, F., Bian, J., Ren, J.-L., Peng, P., Xu, F., Sun, R.-C.: Fractionation and characterization of alkali-extracted hemicelluloses from peashrub. Biomass Bioenergy 39, 20-30 (2012). https://doi. org/10.1016/j.biombioe.2010.08.034

11. Peng, F., Ren, J.-L., Xu, F., Bian, J., Peng, P., Sun, R.-C.: Fractional study of alkali-soluble hemicelluloses obtained by graded ethanol precipitation from sugar cane bagasse. J. Agric. Food Chem. 58, 1768-1776 (2010). https://doi.org/10.1021/jf9033255

12. Xu, F., Geng, Z.C., Sun, J.X., Liu, C.F., Ren, J.L., Sun, R.C., Fowler, P., Baird, M.S.: Fractional and structural characterization of hemicelluloses from perennial ryegrass (Lolium perenne) and cocksfoot grass (Dactylis glomerata). Carbohydr. Res. 341, 2073-2082 (2006). https://doi.org/10.1016/j.carres.2006.04.033

13. Vena, P.F., Brienzo, M., García-Aparicio, M., Görgens, J.F., Rypstra, T.: Dilute sulphuric acid extraction of hemicellulose from Eucalyptus grandis and its effect on kraft and soda-aq pulp and handsheet properties. Cell. Chem. Technol. 49, 819-832 (2015)

14. Saha, B.C., Iten, L.B., Cotta, M.A., Wu, Y.V.: Dilute acid pretreatment, enzymatic saccharification and fermentation of wheat straw to ethanol. Process Biochem. 40, 3693-3700 (2005). https://doi. org/10.1016/j.procbio.2005.04.006

15. Anugwom, I., Mäki-Arvela, P., Virtanen, P., Willför, S., Sjöholm, R., Mikkola, J.-P.: Selective extraction of hemicelluloses from spruce using switchable ionic liquids. Carbohydr. Polym. 87, 2005-2011 (2012). https://doi.org/10.1016/j.carbpol.2011.10.006

16. Froschauer, C., Hummel, M., Iakovlev, M., Roselli, A., Schottenberger, H., Sixta, H.: Separation of hemicellulose and cellulose from wood pulp by means of ionic liquid/cosolvent systems. Biomacromolecules 14, 1741-1750 (2013). https://doi.org/10.1021/ bm400106h

17. Xu, J.-K., Sun, Y.-C., Xu, F., Sun, R.-C.: Characterization of hemicelluloses obtained from partially delignified eucalyptus using ionic liquid pretreatment. BioResources, 8, 1946-1962 (2013). https://doi.org/10.15376/biores.8.2.1946-1962

18. Janker-Obermeier, I., Sieber, V., Faulstich, M., Schieder, D.: Solubilization of hemicellulose and lignin from wheat straw through microwave-assisted alkali treatment. Ind. Crops Prod. 39, 198-203 (2012). https://doi.org/10.1016/j.indcrop.2012.02.022

19. Hromádková, Z., Ebringerová, A., Valachovic, P.: Comparison of classical and ultrasound-assisted extraction of polysaccharides from Salvia officinalis L. Ultrason. Sonochem. 5, 163-168 (1999)

20. Hromádková, Z., Ebringerová, A.: Ultrasonic extraction of plant materials-investigation of hemicellulose release from buckwheat hulls. Ultrason. Sonochem. 10, 127-133 (2003). https:// doi.org/10.1016/S1350-4177(03)00094-4

21. Fernández-Bolaños, J.: Steam-explosion of olive stones: hemicellulose solubilization and enhancement of enzymatic hydrolysis 
of cellulose. Bioresour. Technol. 79, 53-61 (2001). https://doi. org/10.1016/S0960-8524(01)00015-3

22. Saddler, J.N., Wu, M.M., Chang, K., Gregg, D.J., Boussaid, A., Beatson, R.P.: Optimization of steam explosion to enhance hemicellulose recovery and enzymatic hydrolysis of cellulose in softwoods. Appl. Biochem. Biotechnol. 77, 47-54 (1999). https://doi. org/10.1385/ABAB:77:1-3:47

23. Sun, X.F., Xu, F., Sun, R.C., Geng, Z.C., Fowler, P., Baird, M.S.: Characteristics of degraded hemicellulosic polymers obtained from steam exploded wheat straw. Carbohydr. Polym. 60, 15-26 (2005). https://doi.org/10.1016/j.carbpol.2004.11.012

24. Xiaowei, P., Hongzhang, C.: Hemicellulose sugar recovery from steam-exploded wheat straw for microbial oil production. Process Biochem. 47, 209-215 (2012). https://doi.org/10.1016/j.procb io.2011.10.035

25. Palm, M., Zacchi, G.: Extraction of hemicellulosic oligosaccharides from spruce using microwave oven or steam treatment. Biomacromolecules 4, 617-623 (2003). https://doi.org/10.1021/ bm020112d

26. Jacquet, N., Quiévy, N., Vanderghem, C., Janas, S., Blecker, C., Wathelet, B., Devaux, J., Paquot, M.: Influence of steam explosion on the thermal stability of cellulose fibres. Polym. Degrad. Stab. 96, 1582-1588 (2011). https://doi.org/10.1016/j.polymdegradstab .2011 .05 .021

27. Jacquet, N., Vanderghem, C., Danthine, S., Quiévy, N., Blecker, C., Devaux, J., Paquot, M.: Author's personal copy Influence of steam explosion on physicochemical properties and hydrolysis rate of pure cellulose fibers. Bioresour. Technol. 121, 221-227 (2012)

28. Overend, R.P.: Fractionation of lignocellulosics by steam-aqueous pretreatments. Philos. Trans. R. Soc. Lond. A 321, 523-536 (1987)

29. Goering, H.K.: Forage Fiber Analyses (Apparatus, Reagents, Procedures, and Some Applications), pp. 20. Agricultural Research Service, U.S. Department of Agriculture, Washington, D.C. (1970)

30. Sluiter, A., Hames, B., Ruiz, R., Scarlata, C., Sluiter, J., Templeton, D.: Determination of Structural Carbohydrates and Lignin in Biomass. National Renewable Energy Laboratory, Golden (2010)

31. Saeman, J.F., Bubl, J.L., Harris, A.N.D.E.E.: Quantitative saccharification of wood and cellulose. Ind. Eng. Chem. 17, 35-37 (1945). https://doi.org/10.1021/i560137a008

32. Bakker, R.R., Elbersen, H.W.: Managing ash content and quality in herbaceous biomass: an analysis from plant to product. In 14th European Biomass Conference, Paris, France, October 17-21, 2005, pp. 210-213

33. García-Aparicio, M., Parawira, W., Van Rensburg, E., Diedericks, D., Galbe, M., Rosslander, C., Zacchi, G., Görgens, J.: Evaluation of steam-treated giant bamboo for production of fermentable sugars. Biotechnol. Prog. 27, 641-649 (2011). https ://doi.org/10.1002/btpr.580

34. Zhang, J., Deng, H., Lin, L., Sun, Y., Pan, C., Liu, S.: Isolation and characterization of wheat straw lignin with a formic acid process. Bioresour. Technol. 101, 2311-2316 (2010). https://doi. org/10.1016/j.biortech.2009.11.037

35. Sun, R., Tomkinson, J.: Comparative study of lignins isolated by alkali and ultrasound-assisted alkali extractions from wheat straw. Ultrason. Sonochem. 9, 85-93 (2002). https://doi.org/10.1016/ S1350-4177(01)00106-7

36. Allison, G.G., Morris, C., Clifton-Brown, J., Lister, S.J., Donnison, I.S.: Genotypic variation in cell wall composition in a diverse set of 244 accessions of Miscanthus. Biomass Bioenergy 35, 4740-4747 (2011). https://doi.org/10.1016/j.biomb ioe. 2011.10 .008

37. Hodgson, E.M., Nowakowski, D.J., Shield, I., Riche, A., Bridgwater, A.V., Clifton-Brown, J.C., Donnison, I.S.: Variation in Miscanthus chemical composition and implications for conversion by pyrolysis and thermo-chemical bio-refining for fuels and chemicals. Bioresour. Technol. 102, 3411-3418 (2011). https:// doi.org/10.1016/j.biortech.2010.10.017

38. Vanderghem, C., Richel, A., Jacquet, N., Blecker, C., Paquot, M.: Impact of formic/acetic acid and ammonia pre-treatments on chemical structure and physico-chemical properties of Miscanthus $x$ giganteus lignins. Polym. Degrad. Stab. 96, 1761-1770 (2011). https://doi.org/10.1016/j.polymdegradstab.2011.07.022

39. Ebringerová, A., Heinze, T.: Xylan and xylan derivatives-biopolymers with valuable properties, 1. Naturally occurring xylans structures, isolation procedures and properties. Macromol. Rapid Commun. 21, 542-556 (2000)

40. Bian, J., Peng, F., Peng, X.-P., Xu, F., Sun, R.-C., Kennedy, J.F.: Isolation of hemicelluloses from sugarcane bagasse at different temperatures: structure and properties. Carbohydr. Polym. 88, 638-645 (2012). https://doi.org/10.1016/j.carbpol.2012.01.010

41. Rabetafika, H.N., Bchir, B., Blecker, C., Paquot, M., Wathelet, B.: Comparative study of alkaline extraction process of hemicelluloses from pear pomace. Biomass Bioenergy 61, 254-264 (2014). https://doi.org/10.1016/j.biombioe.2013.12.022

42. Liu, K.-X., Li, H.-Q., Zhang, J., Zhang, Z.-G., Xu, J.: The effect of non-structural components and lignin on hemicellulose extraction. Bioresour. Technol. 214, 755-760 (2016). https://doi. org/10.1016/j.biortech.2016.05.036

43. Sun, S.N., Yuan, T.Q., Li, M.F., Cao, X.F., Xu, F., Liu, Q.Y.: Structural characterization of hemicelluloses from bamboo culms (Neosinocalamus Affinis). Cell. Chem. Technol. 46, 3-4 (2012)

44. Wen, J.-L., Xiao, L.-P., Sun, Y.-C., Sun, S.-N., Xu, F., Sun, R.-C., Zhang, X.-L.: Comparative study of alkali-soluble hemicelluloses isolated from bamboo (Bambusa rigida). Carbohydr. Res. 346, 111-120 (2011). https://doi.org/10.1016/j.carres.2010.10.006 